\title{
MODALIDADES DEL BARROCO MEXICANO
}

\author{
$P O R$ \\ MANUEL GONZALEZ GALVAN \\ A Raull Flores Guerrero
}

EL Barroco, en sus manifestaciones plásticas, es uno de los estilos más difíciles de sujetar a cánones formales. Resulta inaprensible casi por definíción, pues, poco dogmático en sus realizaciones artísticas, tuvo por consecuencia una avidez extraordinaria por las novedades y en su proceso evolutivo atropella sus mismos pasos con una fantasia sin límites. El estilo se detenfa poco en los propios descubrimientos y tan pronto se deleitaba en sus creaciones, como las abandonaba indiferente.

Es un estilo que cruza la historia como un sembrador obsesionado que riega semillas y adivina los frutos, pero no los espera; a nosotros ha tocado gozar la cosecha y su abundancia, es tal, que aún no acaba. mos de recontar la variedad de frutos.

Ahora nos encontramos con que el tropiezo es nuestro, cuando queriendo definir globalmente lo barroco, siempre hay obras que escapan a síntesis y no se ajustan a fichero, sin violencia, de tal manera que parece contradictorio aplicar el término genérico de barroco, lo mismo a monumentos de prolijidad agobiante que a obras de sencillísima factura, aunque todas estén unidas por el común hilo espiritual del estilo.

Para el poco conocedor, la versatilidad del barroco resulta un galimatías que se opone como barrera a una comprensión clara del mismo, dificultad que sólo una aplicación laboriosa va dilucidando poco a poco; algunos, fastidiados por el cúmulo de variedades, optan mejor por pasar 
sobre el tema, cuando no tomar una actitud despectiva ante el peculiar modo de ser del barroco, en apariencia ilógico y falto de coordinación.

Para una valoración más esencial, amplia y correcta del barroco, hace falta aún mucha labor de ordenación y catalogación. Las teorías que sobre él se han emitido, algunas muy brillantes, no logran convencer plenamente por las fugas que siempre dejan sentir; es necesario todavía un más profundo análisis formal antes de pasar a teorfas de causalidad. Primero está conocer la obra y después buscar los motivos que tuvo su autor para crearla.

Al hablar aqui de modalidades en el barroco mexicano conscientemente limitamos el tema, sabiendo, por otro lado, que el barroco de México es de lo más representativo con que universalmente cuenta el estilo y así algunas de las consideraciones que sobre México se hacen, pueden ser aplicables o válidas para el resto de Latinoamérica y aún para el barroco europeo, dadas las relaciones y fueros universalistas del estilo.

También hemos de limitarnos a la arquitectura y de ésta, tan sólo a la marcada tendencia decorativa del estilo. Proponemos ciertas modalidades del barroco mexicano, simplemente como ayuda para el análisis y descripción de los monumentos, sin pretender en ningún momento que los términos que damos a las diferentes modalidades definan o representen el valor esencial del estilo.

Aunque refiriéndonos a lo arquitectónico, también hacemos la salvedad de no tratar de analizar los hallazgos espaciales y constructivos del estilo, que ya se adentran más en el valor esencial del mismo, quedando aśl limitados a una ordenación puramente terminológica, referida de preferencia al carácter diferencial que el barroco otorgó en México al apoyo arquitectónico: pilastras y columnas, en las que refleja sus más claros anhelos creativos.

\section{EL FUSTE EN EL BARROCO MEXICANO}

Cuando se nos pidiera describir o aclarar las diferencias entre monumentos de similar riqueza ornamental como son: la Capilla del Rosario en Puebla, la Catedral de Zacatecas y el Sagrario Metropolitano de México, seguramente diŕamos que la mayor diferencia estriba en que el barroco de la capilla poblana es una aplicación de yeserias, una ornamentación de estucos sobrepuesta a la estructura; y entre la Catedral de Zacatecas y el Sagrario de México, la diferencia está en que la pri- 
mera tiene columnas salomónicas y en que el segundo es churrigueresco, pues tiene pilastras estípites. Así, a pesar del barroquismo común y del similar esplendor decorativo, el apoyo arquitectónico es el que nos orienta en la descripción de los monumentos -entendemos aqué por "apoyo" las columnas y pilastras - al considerar salomónico el barroco zacatecano, estípite el metropolitano y en los estucos poblanos la misma ausencia de apoyo arquitectónico como fórmula, nos aclara la supremacía de las ornamentaciones sobrepuestas.

Todos los grandes estilos históricos han mostrado preferencia por algún elemento arquitectónico con el cual expresarse claramente. El clasicismo se refiere en gran parte a los capiteles para marcar las diferencias en sus órdenes; el gótico agota las posibilidades expresivas del arco ojival, que estructural y decorativamente cumple con sus impulsos ascencionales, y al barroco lo vemos satisfacerse en crear novedades referidas al fuste de sus apoyos, con un sentido atectónico, simbólico y decorativo. Transformó columnas y pilastras personalizándolas como propias y esas transformaciones las llevó a una cima en la pilastra estípite. Especialmente el barroco de México se aplicó en los fustes, se deleitó y personalizó de tal manera en ellos, que podemos contar por lo menos seis modalidades de formas distintas en el diseño de apoyos, más otras tres en las que priva la fantasía y lo decorativo. Estas modalidades que el barroco de México fue produciendo siguieron un proceso crono. lógico que, aunque se le puede seguir, no es riguroso, puesto que obras en construcción se interpolaban con otras o se enriquecían con hallazgos nuevos y así novedades plásticas conviven y se realizan al mismo tiempo que sus antecedentes. Fueron frecuentes las repeticiones estilísticas o la construcción de obras semejantes a otras ya muy anteriormente realizadas; y proyectos conservadores paralelos a otros más novedosos y vitales, todo complicado por aislamientos geográficos, circunstancias regionales y gustos estéticos peculiares de mecenas y artistas. No es extraño encontrar que, por los mismos días y en el mismo lugar, se estén labrando sobrias fachadas de perfil aún clasicista con interiores ya muy suntuosos de regocijados retablos ultrabarrocos. Cada monumento sólo es explicable por su conocimiento directo. Sin embargo, se puede seguir un hilo de evolución cronológica que aclara en mucho el proceso formal que guió al barroco y muestra como, de manera lógica, el estilo cierra en México de manera circular su propio ciclo vital, pues empezó con audaces manifestaciones decorativas en los estucos del siglo xvir y concluyó en un recrudecimiento de la misma tendencia ornamental, en el 
ultrabarroco, redondeándose así el ciclo evolutivo y quedando enmarcados dentro de él los descubrimientos en el campo más directamente arquitectónico de los valores espaciales y constructivos, representados de manera formal, simbólica y elocuente por las modalidades que actúan sobre el fuste.

\section{BARROCO ESTUCADO}

Llamamos así esta modalidad puesto que emplea básicamente, para expresarse materiales estucables que reúnen facilidades en el manejo técnico, la economía y la riqueza morfológica, (yeserías para los interiores y argamasa para los exteriores). Su técnica es de modelado y no de labra, por lo que fácil ejecución dio cauce a los mayores alardes de la expresividad barroca. Esta facilidad técnica ayudó a que los estucos marcasen, el primer paso del estilo, en su busca de esplendor y unidad totalizadores.

El barroco estucado se caracteriza por ser puramente decorativo, es por lo tanto anástilo, 1 es decir, no emplea el apoyo arquitectónico pero se sujeta a composición y no rebasa los límites que le marcan los paños en que se aplica; cubre, sin ocultar, pilastras, arcos y bóvedas. Respeta todas las líneas de estructura y composición aún secundarias, como lunetos de bóvedas, intercolumnios, jambas, tímpanos y enjutas. Sus formas rizadas y tupidas con abundancia, no irrumpen exageradamente en el espacio, por lo que conservan un carácter de planimetría y claridad compositivas.

En su riqueza morfológica es sincero al permitir apreciar con toda limpieza las estructuras en que se aplica; su esplendor tiene un tono de serenidad al sujetarse a las direcciones geométricas de la arquitectura que lo recibe. Este respeto a ejes compositivos y planos delimitadores es la mayor diferencia entre esta modalidad del barroco estucado y el ultrabarroco, última forma que habrá de cerrar el ciclo, desbordando l1mites, ocultando estructuras e introduciendo vigorosamente en el espacio volúmenes arbitrarios.

Esta modalidad inicia cronológicamente, en plan monumental, la tendencia decorativa del barroco. Tiene su mayor florecimiento en la segunda mitad del siglo xvir, en las yeserfas de Puebla y de Oaxaca, entre Jas que sobresalen: la Capilla del Rosario y la de San Cristóbal, en Puebla; en Oaxaca, Santo Domingo y el vecino santuario del Santo 
Cristo de Tlacolula. En el siglo xvin se realizaron estucados de gran importancia como son: la decoración de Tonantzintla y los camarines marianos de Ocotlán en Tlaxcala, de Tepotzotlán en el Valle de Mé. xico, y la Santa Casa, en San Miguel Allende, Guanajuato.

Al exterior hubo manifestaciones tan importantes come las fachadas de Tepalcingo y Jolalpan en Morelos. ${ }^{2}$ Mas, en todo el país, el pueblo recogió amorosamente esta tendencia por el esplendor ornamental y aunque los estucos, como modalidad propiamente barroca, terminan su ciclo vital en el siglo Xvin, también el siglo xIx vio filtrarse entre la aridez de sus recetas académicas, persistencias de estucos abarrocados, como en la Capilla de Loreto en Guadalupe, Zacatecas. En Michoacán vino a tener sus más recientes expresiones el estuco ya en los principios de nuestro siglo, con la parroquia de Tlalpujahua y el Santuario Guadalupano de Morelia, en los que al gusto por la ornamentación total de interiores se incorporan el arte de sentido popular y algunas expresiones del Art-Nouveau, complicadas y enriquecidas por la reaparición de la técnica indígena del pastillaje, a base de barro cocido, policromado y pegado.

La pertinaz aparición esporádica de abundantes ornamentaciones, aplicadas sobre estructuras arquitectónicas que no necesariamente tienen por qué recibirlas, nos indica la relativa cronologia con que puede ordenarse esta inclinación del gusto mexicano, la que iniciada y redon. deada en obras barrocas, no impide por esto una continuidad en otras épocas y estilos y así, en consecuencia, aun podemos esperar reapariciones de dicha tendencia aunque ya no referidas completamente al barroco, cuyo ciclo histórico está definitivamente cerrado.

\section{BARROCO TALAVERESCO}

El término "Talaveresco", que se origina en la celebridad adquirida por la población de Talavera de la Reina, en España, donde el arte mudéjar del azulejo adquirió gran perfección, es un nombre apropiado, a nuestro parecer. ${ }^{3}$ Sin embargo, el sentido plástico del azulejo poblano, conserva formalmente poco de su antecedente, si bien, la técnica y algunos diseños de lacerfas y estrellas sí remontan a orígenes mudéjares. El término se justifica y reconoce ya que en la misma época virreinal al azulejo le llamaban "talavera"; quizá también convenga llamar a esta modalidad, barroco "vidriado" o "esmaltado" * por ser más genérico. 
Como una consecuencia complementaria a la esplendidez del batroco estucado interior aparece esta característica modalidad regional de Puebla y Tlaxcala, en la que interviene esencialmente el uso del barro vidriado, azulejo o "talavera". Modalidad que surge impulsada por el deseo de otorgar una fácil y accesible riqueza de ornamentación a los paños exteriores y, sobre todo, por la posibilidad de aplicar una poli. cromia brillante y perenne a fachadas, torres y cúpulas. Ornamentación capaz de hacer vibrar, con policromía, los volúmenes arquitectónicos, en medio del brillo y los contrastes y variaciones luminicas que el sol produce exteriormente, pues con el barro vidriado se vence, espectacularmente, la amenaza de la destrucción del color a la intemperie.

El talaveresco es un desdoblamiento del hervor plástico de los interiores estucados y suele acompañarlos, siendo a la intemperie lo que aquellos a la tibieza y recogimiento de los recintos y, como ellos, sin pretensiones constructivas. Es un barroco de recubrimiento, una manera de piel o de traje que complementa la forma modelándola y protegiéndola. En él no interviene para nada el labrado, es consciente de su función atectónica y ornamental, por lo que, como el barroco estucado, respeta los paramentos constructivos en que se aplica, integrándose a la arquitectura con sentido definidamente pictórico, sin rebasar los límites bidimensionales de muros o el perfil estructural que reviste. Su carácter distintivo es provocar texturas pictóricas sometidas a simetría casi matemática, debidas, en parte, a su misma técnica, donde se alternan rítmicamente los ladrillos vidriados. Sólo encuentra algunas fugas exentas e imaginativas en remates que, aun asf, tienen aspecto torneado por la superposición de elementos de formas regulares, como macetones, jarros, etcétera.

Los antecedentes mudéjares del azulejo y su aplicación en objetos de la vida diaria, hacen del talaveresco un arte suntuario incorporado e integrado magistralmente por el barroco a su evolución arquitectónica, de tal manera que fachadas como las de San Marcos de Puebla, Tlaxcalanzingo o la capilla de San Antonio en Churubusco, si fuesen despo. jadas de su recubrimiento talaveresco, se empobrecerían y quedarían como simples muros desnudos difíciles de incluir en algún estilo definido; en cambio, recubiertas con azulejos adquieren personalidad y categoria.

El talaveresco tuvo sus primeras manifestaciones desde el siglo Xvir, perọ sólo adquiere sistematización y máximo esplendor a mediados del siglo xvir, que es cuando se levantan sus mejores ejemplares. Aunque 
es modalidad limitada a la zona poblana y tlaxcalteca, extiende su acción a todo el país, recubriendo cientos de cúpulas y cantidad de torres y actúa de tal manera en el paisaje que, el burbujear de las medias na. ranjas vidriadas, es distintivo mexicano. Tiene esporádicas manifestaciones monumentales en otras regiones, como la Casa de los Azulejos y el Pocito de Guadalupe en la Capital, y raros ejemplos aislados y remotos, como San José de Campeche, sin duda obra de algún artista del centro del país.

E1 barroco supo usar tan diestramente la viveza y contrastes cromáticos de esta modalidad, que aunque posteriormente y aun a últimas fechas se han hecho intentos por recrearla, no alcanzan el buen gusto y la finura pictórica de su momento dieciochesco.

\section{BARROGO PURISTA}

El barroco purista es modalidad que llamamos así puesto que se reconoce en que, pese a los alardes ornamentales permitidos en los elementos constructivos que complementan o rodean columnas y pilastras, éstas permanecen con sus básicas formas clásicas y estáticas, con sus fustes estriados con nitidez y en el caso de las columnas hasta su curva o gálibo limpiamente trazado a partir del primer tercio. Es el barroco consciente de sus posibilidades, pero respetuoso de la esencial tradición arquitectónica como si dejara patente con esta actitud, la firmeza de sus bases clásicas.

Esta primera modalidad estructural ofrece un vivo contraste entre las columnas y pilastras, tratadas académicamente, y el revoloteo de en. tablamientos, hornacinas y remates sobre ellas. Era lógico que así fuera, puesto que el ejemplo estaba dictado por la misma arquitectura grecoromana, la que, al incorporar el arco a los intercolumpios de origen griego, convirtió entablamientos y frontones en elementos ornamentales. Desde entonces los quiebres y ondulaciones se hicieron presentes en ellos. Las ruinas que nos quedan de termas y arcos de triunfo romanos lo prueban y no es arbitrario remontar a esas épocas un principio de barroquismo, donde lo estructural deviene decorativo y que, pasado por mano renacentista, recibe gustosamente el barroco histórico, como una herencia destinada a ser dilapidada hasta su último límite.

Las formas arquitectónicas greco-romanas y su sistema constructivo lógico y elegante, son aceptados como puntos básicos de arranque por 
el barroco. Debe tenerse siempre en cuenta que al estilo evoluciona par. tiendo de la sobriedad constructiva renacentista y, aun más, en Espańa y sus dominios arranca de la austeridad herreriana, máxima severidad y ascetismo arquitectónico que presupone la actitud religiosa del estilo por nacer y no como es frecuente suponer, que el barroco sea una prolongación de estilos tan ornamentados como el gótico y el plateresco. Esta confusión se explica por las coincidencias de estos estilos en su actitud expresiva de suntuosidad didáctica y religiosa; son estilos hermanos, pero no descendiente el uno del otro.

En un principio el barroco es tan respetuoso de la verdad constructiva, que sólo se atreve a distorsionar y poner en movimiento los elementos sustentados o secundarios de la arquitectura: entablamientos, remates, frontones, etc., pero sin modificar en nada los que representan el equilibrio y estabilidad de la obra como son: columnas, pilastres y pedestales. Puede decirse que el estilo evoluciona transformando los elementos estructurales de arriba hacia bajo, que desciende de la cúspide a los cimientos, comunicando a todo lo que va tocando una pasión y vitalidad plástica deslumbrantes, como un fuego nuevo que consumiera la tradición recibida hasta agotarla. Sin embargo, en un principio actuó con cautela, empleándose los apoyos en toda su sobriedad constructiva y respetó su pureza de molduración, aun cuando no su proporción, con lo que muestra ya su tendencia a cambios volumétricos y espaciales.

Esta modalidad tuvo sus mejores realizaciones en México durante la primera mitad del siglo xvir y por representar una forma culta de arquitectura se muestra más elocuente en obras de importancia monumental, como son los cuerpos inferiores en las portadas catedralicias de México y Puebla, y fue haciéndose extensiva a obras menores, pero no menos representativas, como las portadas de La Compañla en Querétaro, la lateral del Carmen en Morelia, fechada en 1619, la Merced, en Guadalajara y una infindad más, diseminadas por todo el país. Debido a este característico purismo, la modalidad fue accesible y económica en su sencillez, por ello largo tiempo siguió realizándose. No es extraño encontrar en pleno siglo xvill, contemporáneamente a obras del barroco más adelantado, salomónico o estípite, obras de barroco purista.

\section{BARROCO DE ESTRIAS MOVILES}

Le llamamos así porque las estrías adquieren un intenso movimiento, generalmente ondulado o en zigzag, aunque hay casos en que es más 
variado en dibujos geométricos, como en el caso de la iglesia de San Bernardo de México.

Esta modalidad se caracteriza por que las estrías, a todo lo largo del fuste, cambian la línea recta vertical, que siempre habian seguido, por un rítmico moviimento ondulado o en zigzag. Cuando esto sucede en columnas, los perfiles del fuste, el volumen y composición, permanecen fieles a la linea purista, aunque se riza la superficie al moverse la concavidad de las estrias; en cambio, en pilastras adosadas, la modalidad se hace más notable ya que la rigidez tradicional del fuste se quiebra. Cuando el perfil del fuste sigue el movimiento de las estrias ondulantes, lo hacen flexible, le dan aspecto de meandro, y si en zigzag, el efecto es de acordeón o diente de sierra. En cualquier caso, el fuste pierde su carácter de masa rígida mostrándose flexible.

Esta modalidad sigue a la purista, puesto que es el segundo paso del arte barroco, aunque es elemento secundario que respeta el núcleo esencial de los fustes. Como aplicación barroca, si bien elemental y con escasos ejemplos, es importante y significativa, puesto que muestra la inquietud $e$ inconformidad del estilo ante la forma de los apoyos tradicionales y es ya una primera actitud más conscientemente anti-clásica.

Las estrías móviles tienen una vibración y nerviosismo que, aunque todavía contenidos, anuncian los cambios mayores que en adelante obrará el barroco. Parece que un temblor interno agitara el fuste, éste empieza a perder su clásica impasibilidad, se mueve perdiendo seguridad constructiva, su anterior afirmación de fuerza estructural.

La estría móvil comunica a la totalidad del fuste un aspecto nervioso y sus ondulaciones presagian el esencial movimiento volumétrico que habrá de traer la helicoide en el barroco salomónico. La superficie se riza, como la del agua; el efecto, rico en texturas y sugerencias, hizo que esta modalidad, aunque no con ejemplos muy frecuentes, sobreviviera paralela a las que le siguieron e hiciera acto de presencia de manera esporádica pero continua.

Sus antecedentes son oscuros, pues los ejemplos escasean en la misma España, aunque existe un ejemplar esplendoroso en la portada de San Telmo, en Sevilla. Su cronología es difícil de concretar; su presencia es prematura en la iglesia de Regina, en México, y en algunos ejemplares poblanos, y es extemporánea en la Capilla del Salto del Agua, ya de tines del siglo xvir. Tiene su momento de esplendor a principios del siglo xvir en la obra de Miguel Custodio Durán, que hace de los fustes con estrías móviles sus preferidos, dándoles un empleo muy personal, al 
grado de ser lo característico en sus obras. Son de él, en la Capital, las columnas onduladas en el primer cuerpo de la portada de la iglesia de San Lázaro y se le atribuyen las pilastras en las portadas de la iglesia de Regina; en esta última, en la capilla interior, donde las pilastras ondulantes comunican su movimiento a la cornisa y los remates, adquiriendo todo el conjunto un espléndido efecto, es en donde lucen mejor las formas empleadas por Durán.

Otros ejemplos en la Capital son: el primer cuerpo en la fachada de la iglesia de San Fernando, con columnas de estrfas onduladas; el primer cuerpo en las portadas de la iglesia de San Bernardo, donde las columnas en la parte inferior enriquecen el movimiento de las estrías con trazos mixtilíneos, similares a los de San Telmo de Sevilla. En Pue. bla, destaca la casa del Canónigo Peláez (hoy Academia de Bellas Ar. tes), en cuyo patio las columnas tienen estrias zigzagueantes en el primer tercio y onduladas en el resto, mismas que se continúan en los arcos dando al conjunto un original aspecto de algo orgánico y fluyente.

Las estrías móviles se incorporaron también a otras modalidades del fuste barroco, sobre todo a las de fustes en forma de tablero y a las que acentúan volumétricamente el primer tercio. Custodio Durán empleó estas combinaciones. Los tableros ondulantes llenan totalmente su preciosa fachada cóncava de San Juan de Dios, en la Capital y puso en el segundo cuerpo de la portada de la iglesia de San Lázaro estrías onduladas combinadas con el primer tercio acentuado. Todavía más, Guerrero y Torres, ya en las postrimerías del estilo, emplea tableros ondulantes en las portadas laterales de la Capilla del Pocito en la Villa de Guadalupe. Su gusto por el meandro, dominante en el palacio del Concle de San Mateo Valparaíso, tal vez surja de la contemplación de esta modalidad en obras anteriores.

Para hacer patente la aceptación y difusión de la estrfa móvil en México bastará con citar su presencia en las grandes catedrales, como en el segundo cuerpo de la portada mayor de la de México, donde aparecen combinados el zigzag, en el primer tercio, y la ondulación en el resto, en forma totalmente similar a como aparece también en las portadas de coro de la catedral de Puebla.

\section{BARROCO TABLERADO}

Esta modalidad tiene como distintivo el uso exclusivo de pilastras, cuyo fuste en volumen, plano y perfil de rectángulo alargado se presta 
a las libertades del barroco. El fuste de una pilastra, por sí solo, sugiere un tablero que sirve de fondo a otros elementos ornamentales y en el que pueden grabarse acanalamientos o sobreponerse otros tableros de varios diseños, siempre en plan bidimensional. Por esto llamamos "tablerados" a los fustes asi dispuestos.

El barroco de fustes tablerados se emparenta e identifica con esas expresiones, tan austeras como inquietas, que en España llaman "de aplicaciones" y que tienen en Galicia sus mejores ejemplares. *

En esta fase del barroco se deja sentir una fuerte influencia del mobiliario, con mayor energia que en otras. Pedestales y fustes son, con trecuencia, versiones pétreas de tableros de puertas, hojas de alacenas y apoyos de muebles; aparecen en ellos molduraciones perimetrales, simétricas y limpiamente trazadas, como si fueran talladas con gubia y escoplo y no con los requiebros que permite el cincel. La ornamentación vegetal se ausenta para ceder lugar a trazos mixtilíneos de curso planimétrico, característica que viene a lograr pleno desarrollo con la incorporación a la arquitectura de las guardamalletas, esas movidas placas mixtilineas que como faldones planchados alegran y enriquecen las estructuras. Es de considerarse la influencia que sobre el ánimo de los arquitectos haya tenido el aspecto de las calles en las festividades y procesiones, cuando los gallardetes ondeaban sobre las fachadas y los ricos mantones y brocados pendían de los balcones. Así, la guardamalleta vino a cubrir muros y a colgar de capiteles y repisones de ventanas, añadiendo un aspecto de fiesta y suntuosidad perenne a los monumentos barrocos y a dar satisfacción a las inclinaciones mixtilíneas del estilo. La guardamalleta llega a ser un elemento formal representativo del barroco, a semejanza del arco apuntado y la aguja en el gótico o los capiteles del clasicismo. Es elocuente la comparación entre el uso naturalista que otros estilos, como el plateresco, dan a paños y listones que verdaderamente se amarran y enredan en la arquitectura como algo extraño, y la respuesta geométrica, simétrica, audaz y perfectamente integrada que la guardamalleta alcanza en el barroco, a tal grado que, posteriormente, ella misma sirve de recipiente arquitectónico a las añadidas guirnaldas naturalistas, que al avanzar el estilo, gustó emplear para cubrir sus retablos dorados y fachadas.

El barroco tablerado muestra en forma rotunda y clara la actitud absorbente, ecléctica y transformadora del estilo; basta ver como convierte el almohadillado renacentista en un ritmo de tableros enmarcadores, como sucede en la casa del conde de la Cortina y en la casa de 
Borda, o en la entrada al convento de San Hipólito, todos estos ejemplos en la Ciudad de México. Puede asegurarse también, que es la modalidad más usual y predominante en la arquitectura civil de todo el virreinato, principalmente en las ciudades de México, Puebla, Morelia, Querétaro, Guanajuato y San Miguel Allende.

El barroco tablerado produjo sus mejores ejemplos a partir de mediados del siglo xvi hasta mediados del siglo xvirı. Llena con sus obras principalmente la zona central del pais. Tiene expresiones cumbres en ciertos monumentos; como la catedral de Morelia, iglesia que, en todo el esplendor de sus fachadas y torres, no tiene un solo fuste circular o galibado y en cambio sf infinidad de pilastras tableradas; lo mismo sucede en otros templos morelianos como Las Rosas y San José. En arquitectura civil son notables los palacios de la Capital, como el Palacio Real, o de los Virreyes, la Aduana de Sto. Domingo, La Inquisición y Las Vizcafnas; en Querétaro, el del Marqués de la Villa del Villar; en Morelia, el Seminario (Hoy Palacio de Gobierno) y muchos más en todas las ciudades importantes del virreinato.

\section{BARROCO TRITÓSTILO}

Por no encontrar un término adecuado en los diccionarios arquitectónicos, nos hemos visto precisados a formar esta palabra para señalar la modalidad que acentúa el primer tercio de las columnas, con las raíces griegas: tritos $=$ tercio y stilo=columna. Columna que acentúa o marca tercios del fuste.

De manera consecuente con la posición ecléctica del barroco, aparece esta modalidad de acentuar vigorosamente en el fuste un tercio, generalmente el primero, solución de antecedentes clásicos y por tal razón también frecuente en el renacimiento y en el plateresco.. Pero aunque basada en estos orígenes, la columna tritóstila barroca, no tiene porqué confundírsela con aquéllas, pues si la apariencia es a primera vista similar, un más detenido análisis delata el carácter que el barroco lo infundió haciéndola más distorsionada, menos lineal y más escultórica. Ya en la Grecia helenística, el fuste de las columnas dividía su gálibo en tres partes y dejando el tercio inferior totalmente vertical. En la Roma Clásica, son frecuentes el jónico y el corintio marcando con gran finura la verticalidad del primer tercio, por medio de la caña o estrfa convexa, que alojada en la estría cóncava, asciende con ella hasta la al- 
tura del primer tercio, de donde arranca la curvatura del gálibo. Con esto se logró hacer más perceptible la forma apiramidada del fuste el que disminuyendo el diámetro al llegar al capitel, consigue así mayor resistencia a la ruptura vertical. Esta función constructiva se delata marcando la caña en el primer tercio y dejando libre la estría a lo largo del gálibo en el resto del fuste. Tal refinamiento clásico fue acentuado en algunos casos, sobredecorando el tercio y añadiendo además, para mayor esbeltez, la base ática; en esto, Roma siguió la línea escultóricoarquitectónica del templo de Artemisa en Efeso. Lo mismo hizo el rena. cimiento y por tanto el plateresco, debiendo tomarse en cuenta que este último reiteró con insistencia los fustes decorados con figuras humanas en el primer tercio, angelillos o santos, y añadió como el renacimiento, lienzos enrollados y sujetos al collarín del capitel, con lo que la columna alcanza esa gran suntuosidad que el barroco no podía pasar por alto. Pero como el barroco en su fogosidad olvidaba la ponderación recibe la columna tritóstila y la varia a su gusto, exagerando sus caracteristicas. Para el barroco no se trataba de delatar la función del fuste, ni de ornamentarlo graciosamente, sino de comunicarle una expresividad vibrante; no se trataba solamente de revestir la columna, sino de moverla y, así, el primer tercio, como impulsado por un resorte, crece, asciende, se ensancha y llega a trepar usurpando sitios que no le corresponden a lo largo del fuste; aparece ast "la locura barroca", con gálibos exagerados hasta el estrangulamiento, capiteles frondosos que parecen desgajarse con el peso del entablamento, basas áticas que se superponen y lanzan anillos hasta mediados del fuste, ornamentaciones vegetales y geométricas tan llenas de vitalidad que rompen límites y ahogan figuras escultóricas dejando asomar solamente de vez en cuando rostros como mascarones semivegetales. Las estrias se contagian de este impulso vibrante y adquieren una ondulación y zigzagueo nunca antes visto. La columna tritóstila barroca, conserva pues, todavía, un disfraz de serenidad clásica, pero con una impresión de fuerza contenida a punto de liberarse, sobre todo en ejemplos del siglo xvur. El perfil exagerado de algunas de estas columnas, puesto al lado de las más atrevidas de sus antecesoras, es el mejor argumento de su gentilicio barroco. La ornamentación en columnas tritóstilas del clasicismo se abraza al fuste como temiendo marchitarse lejos de él; en el barroco, esta misma ornamentación brota con tendencia al avance espacial, busca desprenderse, liberarse más que uncirse.

En México la modalidad tuvo su apogeo en los ańos fronterizos de los sigios XVII y Xvir. ${ }^{\top}$ Hubo artistas representativos que hicieron de ella 
su principal forma de expresión, como acontece en las obras de Pedro de Arrieta. Hubo también ciudades que dieron preferencia a esta colum. na, poblando el aire urbano de sus templos y palacios con ella, tal es Oaxaca, en la que su catedral tiene la fachada mayor toda tritóstila, repitiéndose esta columna también en las portadas de San Agustín y la Soledad, de la misma ciudad. En Guadalajara, San Felipe Neri es otro monumento en el que el barroco tritóstilo adquiere gran monumentalidad y elegancia. Cuando el estilo declinaba al finalizar el siglo xvirr, un arquitecto como Francisco Antonio Guerrero y Torres, volvió a usar el apoyo tritóstilo dándole una última vigencia, como si presintiera el regreso del clasicismo que volvía con intenciones depuradoras a poner punto final a las exageradas libertades que en ausencia de academismos se permitió el barroco; aś, aplicó la modalidad en la iglesia del Pocito, en Guadalupe, y en la portada de La Enseñanza, que se le atribuye.

\section{BARROCO SALOMÓNICO}

El uso de la columna llamada salomónica es una de las modalidades más distintivas del barroco, tanto que la generalización que de ella hace el estilo la ha popularizado, elevándola casi a categoría de símbolo. Todos los países en que el estilo haya dejado huella importante de su paso, cuentan con ejemplares salomónicos y en algunos adquiere supremacia predominante, principalmente en zonas del centro europeo y Sudamérica. Como en tantos otros casos de la historia del Arte, el término salomónico, con el que se identifica la columna helicoidal, adolece de equívoco, aunque el empleo del término se ve justificado por una larga tradición. En San Pedro de Roma se conserva una columna helicoide enviada como regalo al Pontifice por un sultán en la segunda mitad del siglo xv. Esta columna se supuso pertenecía al templo levan. tado por Salomón, y se la recibio con veneración por creerse, en consecuencia, que el mismo Cristo predicaba cerca de ella. En realidad es una columna de algún palacio de Jerusalén construido por el helenista y romanizado Herodes Agripa, en el siglo primero después de Cristo. La religiosidad contrarreformista, y el deseo de un nuevo arte del agrado divino, como lo habla sido el templo de Jerusalén, la puso de moda y se la revaloró arquitectónicamente llevando el ánimo de algunos investigadores, como el benedictino Juan Ricci, a considerar la helicoide como de inspiración divina y fue él quien empezó a llamarle "orden 
salomónico". El prestigio b́blico y judaico de la columna salomónica respondió a los anhelos religiosos y estéticos renovadores del barroco triunfante; así, Bernini la toma de modelo y levanta con ella el gran baldaquino de bronce bajo la cúpula de Miguel Angel, en el corazón mismo del templo máximo de la cristiandad. Cuando esta obra se termina en 1633, nace de golpe, ya maduro y prestigiado, el barroco salomónico.

Por su fórmula plástica, la columna salomónica debe llamarse más correcta y concretamente, helicoidal, aunque es dificil olvidar el calificativo aceptado y reconocido por siglos.

Para el barroco lo importante es que este fuste respondió simbó. lica y formalmente a su búsqueda de estructuraciones arquitectónicas distorsionadas y movidas, sugestivas religiosamente y con un crédito tra. dicional tan importante como el de las formas greco-romanas. El interés que en el fuste helicoidal puso el estilo, se debe a que no sólo es un apoyo ornamentado o enriquecido en sus perfiles, sino que sugiere aligeramiento e imponderabilidad de los entablamentos y cargas que recibe. Produciendo psicológicamente la sensación de un impulso siem. pre ascensional, cosa muy satisfactoria para el barroco.

Las columnas y pilastras antecedentes, más ligadas a lo clásico, recuerdan su función de recibir y transmitir cargas al piso, permanece en ellas manifiesto un esfuerzo descendente, impulso acentuado cuando se presenta el gálibo; en cambio, la helicoide, más parece empujar hacia arriba, como un tirabuzón que taladra vigorosamente y es apenas sosegado por el capitel, pero cuya vibración acaba por transmitirse a los pedestales y entablamentos haciéndolos también ondulantes. El barroco helicoide muestra una plenitud esencial que dominante y segura de si misma, se permite entonces el esplendor de cualquier revestimiento ornamental y así al pasar a tierras de España y sus dominios, se baña en rizos vegetales, generalmente la vid eucarística. Por otro lado, hay fustes puristas a los que se enredan vegetales con intención salomónica, pero nunca llegan a serlo en realidad, puesto que no existe la esencial helicoide. 8 .

Para el caso mexicano, es en la segunda mitad del siglo xvir cuando este barroco llega a la plenitud. En fachadas y retablos de estos afíos domina la helicoide, y es tal el fervor y gusto puesto en ello, que al fuste salomónico se incorpora el distintivo tritóstilo para af́adir así mayor agitación; monumento representativo de ésto, es la Catedral de San Luis Potosí. Desde luego, esta fusión salomónico-tritóstila, no es 
privativa de ningún país, sino un producto lógico de este atropellar sus propios pasos que tiene el estilo, confundiéndolos y combinándolos como si pretendiera alcanzar el plano de la musicalidad plástica.

El barroco helicoide, entre nosotros, fue ausentándose hasta que lo pudo desplazar otro apoyo más contrastado y de mayores alardes atectónicos: la pilastra estípite; pero dejó en tanto obras señeras, como la fachada catedraliica de Zacatecas, la ya citada Catedral de San Luis, Santo Domingo en San Cristóbal las Casas y otras, como San. Francisco y Santa Mónica de Guadalajara y un sinnúmero más en otras ciudades, aparte de infinidad de retablos en donde la helicoide se ahueca simulando una trenza anticonstructiva, como en algunos retablos de San Francisco de Tlaxcala, sintomáticos ya del agotamiento a que llegó la modalidad por sí misma.

\section{BARROCO ESTIPITE}

El estípite es una pirámide de vértice muy alto, truncada e invertida. ${ }^{\circ}$ Ya los griegos lo usaron con abundancia y gustaban ponerlo como pedestal para bustos de dioses y héroes, con lo que estos bustos sugerían así representar la figura humana completa al estar sobre este cuerpo geométrico. Los romanos, y posteriormente los renacentistas, continuaron realizándolo en la misma forma y estos últimos lo incorporaron a las estructuras arquitectónicas, otorgándole categorfa de pilastra, por lo que aparece sobre él un capitel, o bien, el busto emerge con todo el torso y levanta las manos sirviendo como atlante o cariátide. Mas, en estos casos, permanece un cierto contraste, no siempre agradable, una falta de integración total entre las formas naturales de torsos, rostros y brazos, con el resto geométrico y estático del estípite. Es hasta el barroco cuando el estípite alcanza una perfecta incorporación como integrante básico en la organización estructural de una pilastra. En España, a José Benito Churriguera corresponde el mérito de mostrar por primera vez, ya organizada, la pilastra estípite como habrá de ser difundida por el barroco, constando básicamente de cuatro elementos; basa, estípite, cubo y capitel; esto acontece en la, por ello célebre, pira funeraria de María Luisa de Orleans, erigida por Churriguera en 1689. En adelante, el barroco hará de ella en la misma Espańa y sobre todo en México, su apoyo más representativo, popularizando el nombre de su autor. El nombre de "Churrigueresco", aunque justamente honra al conformador de la 
pilastra, no siempre puede aplicarse de manera arbitraria o indiferente a obras de otros arquitectos que la emplearon y difundieron, y quienes en realidad la impusieron, perfeccionaron y dieron crédito. En España, Pedro Ribera, en México Jerónimo de Balbás y Lorenzo Rodriguez, alegarían derechos similares para designar con sus nombres al estilo. El barroco estípite de Nueva España es un fenómeno artístico milagroso, comparable a los momentos más esplendorosos que en la historia del arte han tenido otros paises, como la Francia gótica del siglo xin, la Italia renacentista, o la España plateresca.

Gloria de México es poseer la más extraordinaria cantidad, calidad y variedad de pilastras estípites de que país alguno pueda ufanarse; en ello no tiene rival y por esto se ha llamado estilo nacional, al barroco estipite.

Dentro de normas lógico constructivas, esta pilastra es el último alarde innovador del barroco. A la vez que cima en el proceso evolutivo de los fustes empleados por el estilo, el estípite es polo opuesto al sentido constructivo clásico, pero por extraño y paradójico que parezca, constituye también el apoyo de más remotos antecedentes, pues hunde su historia en la cultura cretense, donde aparecen los primeros ejemplos de fustes en que la gravedad parece invertirse o negarse, como acontece en las columnas cónicas del palacio de Knossos.

Es importante constatar cómo el barroco, en este momento de aparente falta de lógica constructiva, es sin embargo, lúcido y en el fondo clasicista, tanto en las directrices compositivas que emplea, como en la persistencia de elementos clásicos y en los detalles de molduración. Puede decirse que los hallazgos barrocos son las últimas palabras vitales del vocabulario formal clásico. El posterior purismo neoclásico no supo reconocer esto en el barroco y revaloró lo grecorromano con actitud académica, retrotrayendo el proceso histórico, por lo que cayó en la copia repetida y la receta, ocasionando la verdadera muerte de lo clásico por parálisis. Cuando el neoclásico es más vital, como acontece en algunos arquitectos de fuerte personalidad, o en las libertades que se permitian las interpretaciones populares, es cuando más se abarroca. Suprimiendo al barroco, el neoclásico cegó una fuente que del clasicismo se alimentaba aunque ella misma no lo creyera y proclamara negarlo. La pilastra estípite lo prueba, al ser el último apoyo arquitectónico en que un estilo histórico emplea, de manera sistemática y novedosa, la herencia clásica; basta ver sus molduraciones, sus capiteles siempre corintios o compuestos, sus basas áticas o toscanas y la propia presencia del estipite. Ade- 
más, como lo ha observado De la Maza, es una abstracción del cuerpo humano, por sus correspondencias del capitel con la cabeza, el cubo con el pecho, los estrangulamientos con el cuello y la cintura, el estípite con las caderas y las piernas y la basa con los pies; en esto es, por tanto, de un simbolismo franco y tan humanista o más que la misma Grecia, donde se consideraba al dórico, robusto y sobrio, como representativo de lo masculino y al jónico, más esbelto y curvo, de lo femenino. Los romanos llegaron a presentarla sexuada pero la pilastra estípite barroca, en su asexual y rigurosa abstracción, está más cerca de lo humano que aquéllas interpretaciones hechas sobre lo clásico.

La modalidad tuvo su manifestación del primer tercio a fines del siglo xvilI y duró unos escasos cincuenta años, apenas una generación, pero alcanzó una increible difusión geográfica y numérica, tanto que sería difícil un inventario exhaustivo. La mayor área del país refulge de retablos dorados y riquísimas fachadas; imposible describir la variedad formal y material a que dió lugar la versatilidad del estípite, muchas veces irreconocible y oculto bajo cataratas de ornamentación. El fuste de la pilastra estípite con su juego de volúmenes, permitió los mayores alardes plásticos y en México, sólo una vista detenida a su sinfín de iglesias y un más profundo análisis de sus retablos y exteriores, permite formar una idea de la magnificencia que en el país mostró esta modalidad barroca. Deslumbran a críticos e historiadores los caracteres regionales; la imaginación poblana, la finura guanajuatense y la riqueza queretana y potosina. Basten sólo dos ejemplos elocuentes, el retablo de Los Reyes en la catedral de México, con los cuatro estípites más colosales y vigorosos del mundo, introductores de la modalidad en México, y la fachada de Tepotzotlán, la de mayores proporciones, la más monumental que levantó el barroco estípite.

\section{ULTRABARROCO}

El término de "ultrabarroco", inventado por el Dr. Atl para denominar el delirio final alcanzado por el barroco mexicano, especialmen. te en la obra de retablos, es muy adecuado y significativo, ${ }^{10}$ sólo que conviene dedicarlo en especial y para mayor exactitud, a las últimas producciones en las que el estípite definidor desaparece o se desintegra a tal grado que se hace irreconocible al perder sus perfiles geométricos, distorsionado por excesos imaginativos. La palabra misma de ultra- 
barroco, nos indica su referencia a lo que está más allá de los propios cánones del estilo, aunque permaneciendo sujeto a él.

El ultrabarroco fue el último paso que se podia dar; agonfa gloriosa y deslumbrante que tuvo el estilo antes de caer en la franca decrepitud que se anunciaba.

Diego Angulo Iñiguez analiza con detenimiento, en su Historia del Arte Hispanoamericano 11, esta última fase del barroco mexicano y encuentra que el interestípite, elemento ornamental enmarcado por las pilastras estípite, va cobrando primacía hasta desplazar los apoyos y constituir por sí solo todo el argumento compositivo. Desde el momento en que la pilastra estípite desaparece como eje arquitectónico reconocible, puede considerarse presente el ultrabarroco, aun cuando en el interestípite se conserven pretensiones estructurales, al tener en su parte inferior pedestales y basas, y en la superior, capiteles y entablamentos, o aun cuando aparezcan, como es frecuente, pilastrillas estípites empequeñecidas o en plan totalmente secundario, como si indicaran ya su lejanía presurosa antes de acabar por desaparecer. En el ultrabarroco, la parte correspondiente al fuste, la esencial como apoyo, se desintegra en forma arbitraria; los límites se desbordan, no se observa regla ninguna y la fantasía del diseñador desconoce riendas.

En ninguno de los estilos anteriores, alimentados por elementos clasicistas, se habia dado jamás un fenómeno de inversión tan notable como el acontecido en el intercolumnio ultrabarroco; los intercolumnios fueron siempre parte secundaria en la composición, especie de relleno al que se atendía como complemento, si bien ornamentándolo y ligándolo armónicamente con el resto. Los intercolumnios eran recipiente de símbolos: esculturas, escudos, inscripciones, etc.; fue lógico que el barroco con su exacerbada inclinación a lo simbólico-expresivo, terminara atreviéndose a proclamar la superioridad de ello por sobre lo lógicoconstructivo. En el intercolumnio van, generalmente, hornacinas con santos y, a consecuencia de ello, por siglos vivió en segundo plano, sirviendo de fondo a la composición estructural de apoyos y entablamentos; ahora, animado por la religiosidad barroca, hace su revolución, se abandera en el interestípite, avanza arrollando lo que le rodea, deja en segundo plano las pilastras, se hincha, las desplaza y llega a componer todo en torno a los símbolos y hornacinas con esculturas, el interestipite deviene así en la pilastra nicho, estudiada por Joseph Baird. ${ }^{12}$ Se aplana y extiende, o avanza formando ricos volúmenes ornamentales, cuando esto sucede, no se trata pues, de un nuevo apoyo organizado, 
sino de la supeditación de todo lo estructural a lo puramente simbólico y decorativo, por esto, una vez desintegrados los apoyos, ni siquiera el nombre de interestípite corresponde con precisión, puesto que las formas ya no están en medio de nada, son libres y se justifican en sí mismas; es un más allá de los cánones, justamente, un ultrabarroco. Sin embargo, hasta los últimos momentos, quedan restos de elementos y distribución compositiva arquitectónica, aunque no ya de estructuración, asi aparezcan, como tras una explosión, capiteles, basas, pedestales y entablamentos fragmentados. En este momento, todo cae en lo decorativo, concluyendo y cerrándose el ciclo barroco que en las yeserias y estucos, también en plan decorativo, se había iniciado. Los últimos retablos adquieren carácter de mobiliario, no tienen ligazón con el resto del edificio, las esculturas se mueven independientes entre frondas doradas, selvas enmarañadas en su talla que parecen esperar sólo un golpe de viento para moverse físicamente. Los retablos tienen aspecto delicuescente y el no seguir ninguna línea directriz es lo que diferencia más notablemente la decoración ultrabarroca de la de estucos. En las yeserías y estucos anteriores, la planimetría y el respeto a los diques de bóvedas y muros que las contienen, dan un aspecto de moderación y serenidad por tupidos que sean. En el ultrabarroco todo es imprevisto, se extiende, avanza o retrocede briosamente, sin importar límites. En unos casos, como jugando, en otros, con delirio imaginativo o desazón, al final, con cansancio. Hasta que esta agonía fue, por fin, ahogada por la mano imperativa del neoclásico. El proceso ultrabarroco fue bruscamente cortado en plenitud, con lo que se aureoló de martirio y así, pocos estilos han desaparecido enmedio de tal esplendor y diciendo tan magnificas últimas palabras.

Por su incontrolable espontaneidad, el ultrabarroco es todo un capitulo importante del barroco, en cuya formación convergen razones sociológicas, polfticas, económicas y religiosas, de manera que las consecuencias formales de ellas, resultan de gran interés para su estudio. ${ }^{13}$ Baste con citar las increibles pilastras guardamalletas exentas que valientemente rematan los retablos laterales del Carmen potosino, con su fuste de ágil trazo planimétrico y mixtilíneo; estas pilastras son de 10 más significativo que, en relación con las consideraciones anteriores, nos heredó el ultrabarroco.

En cuanto a fachadas, la modalidad dejo escasos ejemplares, puesto que a su aparición casi todas las importantes estaban conclufdas y sólo la labor de terminados interiores permitió que el ultrabarroco trabajara 
en retablos y muebles, pero las hay notables como el caso monumental de la portada parroquial de Lagos, en Jalisco y otras como la lateral de Valenciana en Guanajuato, la lateral de San Agustín en Zcatecas y la tercera orden de Santo Domingo en Querétaro. En cuanto a lo civil, la Alhóndiga de Morelia.

Pero del ultrabarroco, los retablos fueron lo más extraordinario; en la Capital destacan los de la iglesia de La Enseñanza y los de la iglesia de La Piedad (hoy en Churubusco) y el gran retablo de la capilla de San José, en Azcapotzalco; en Guadalajara, el colateral de Aranzazú; en Taxco, el del Pilar en Santa Prisca; y, por sobre todo, en la zona del Bajío, los retablos del Camarin de la Santa Casa, en San Miguel Allende; en Salamanca, los de San Agustín; en Querétaro, los de Santa Rosa, y como típico ejemplo final, los retablos queretanos de Santa Clara, últimas monumentales creaciones ultrabarrocas antes de la desaparición del estilo.

\section{SALVEDADES}

Todos los monumentos del barroco mexicano, desde la minúscula capilla a la gran catedral, o de la casa hacendaria al palacio urbano, si muestran en alguna parte fustes arquitectónicos o aplicaciones ornamentales, necesariamente reconocen alguna o varias de las modalidades consideradas, mas como toda regla se confirma por sus excepciones, también necesariamente debemos hacer algunas salvedades.

La principal es la de la aportación popular, que en su ingenuidad carente de prejuicios hace florecer, a la sombra de los monumentos bien proyectados y premeditados, sus improvisaciones. En el arte popular no hay más norma que la del gusto espontáneo o la imitación azarosa del arte culto. Por su misma liberalidad, las producciones populares no pueden ser claramente incorporadas a corrientes estilfsticas, pues en su esencial falta de normas no reconocen antecedencias ni pretenden trascendencias; son producto aislado de un momento, un medio y una circunstancia, por más que en ellas pese y se reconozca con firmeza la influencia del arte mayor. El arte popular se desarrolla de manera marginal, como planta de río que vive y se alimenta en él, pero sin pertenecer a su corriente. Por eso no es extraño encontrar composiciones populares en las que el barroco muestra mezclas un tanto absurdas o desvirtuadas de sus propios valores y modalidades. 
Por otro lado y en forma consciente, la arquitectura barroca condicionada por gustos regionales o caprichos personales, tiene también expresiones aisladas de originalidad exclusiva que, por su poca difusión o escasos ejemplos, no afecta las consideraciones generales anteriormente estudiadas, tal es. el caso de las peculiares iglesias oaxaqueñas de San Felipe y la Compañía, donde la composición y ornamentación barrocas se estructuran en torno a purisimas columnas candelabro de origen plateresco. $O$ el caso de las singulares columnas y pilastras potosinas que marcan no sólo uno, sino los tres tercios del fuste, dándole distinto tratamiento y textura a las secciones; esta modalidad regional es importante y original y llegó a extenderse a otras regiones, apareciendo espléndida en el convento de Guadalupe en Zacatecas. Sin embargo, estos fustes son relativamente escasos en el panorama general del barroco mexicano y no hacen una rigurosa distinción de la modalidad tritóstila sino que más bien, constituyen la muestra más eufórica y exaltada de ella, por esto no se les clasifica especialmente aunque se debe tener en cuenta su interés como equivalentes al exclusivismo de las columnas plateresco-barrocas de Oaxaca.

Otro tanto sucede con ese tipo de fustes puristas cubiertos de ornamentaciones vegetales que a ellos se enredan presintiendo o recordando lo salomónico, mas nunca llegan a serlo plenamente, puesto que la esencia del salomónico es el fuste helicoidal, es decir, el movimiento en la estructura interna, no sólo las simuladas ornamentaciones exteriores. Estos casos deben considerarse como interpretaciones hibridas o como apoyos de intención salomónica, ligados a esta modalidad, aunque sin pertenecer totalmente a ella. Un ejemplo de ello es la iglesia de San Felipe Neri, en San Miguel Allende.

Ahora bien, ampliando la visión, debe tenerse presente que de localismos sembró el barroco la geografía de Latinoamérica y fustes caprichosos también los hay en Sudamérica y en la antigua Capitanía de Guatemala; en estos son distintivos los ricos fustes de sección monorritmica.

La prolifica creatividad barroca no debe asombrarnos, más bien hemos de preocuparnos por aclarar y aprender el vocabulario formal que empleó y así dialogar con el estilo en su propio idioma.

A nadie extraña la descripción de las composiciones clasicistas para las que es necesario un nutrido repertorio de términos en torno a los cinco órdenes. Si una fachada clásica puede organizar sus cuerpos con el Dórico, Jónico y Corintio, y así la describimos, no hay razón para 
que una barroca no pueda alternar sus modalidades y sea purista, salomónica y tritóstila a la vez. El clasicismo, con su gran crédito formal, necesita infinidad de términos secundarios para ser descrito; con el barroco puede y debe hacerse otro tanto.

La creatividad barroca dió giros especiales a las formas tradicionales y por muy mezcladas combinadas o transformadas que estén sus moda. lidades, siempre es posible describir y analizar sus creaciones, desde la generalidad compositiva hasta el más mínimo detalle, sólo haciéndolo asi aprenderemos plenamente sus formas.

Si el clasicismo emplea básicamente cinco órdenes, el barroco de México luce sus nueve modalidades; cinco, como las clásicas, son cons. tructivas, y tres son de esencia decorativa.

El barroco tiene su propia sintáxis arquitectónica; respetándola y siguiéndola se nos hace más accesible.

Basten dos ejemplos significativos: ante la rica fachada de la iglesia de San Francisco Acatepec, en Puebla, lo primero que se nos impone es su total recubrimiento "talaveresco"; los fustes de sus cuerpos son: el primero "tritóstilo", los dos segundos "estípite" y la torre, "salomónica".

Ante la fachada de la iglesia de la Soledad, en Oaxaca, nos impresiona su armoniosa unidad de cuatro cuerpos, todos distintos; el primero es "purista", el segundo "tritóstilo", después otro es "salomónicotritóstilo" 9 el último es "tablerado", todo bella y vigorosamente coordinado por el barroco.

\section{SINTESIS DE LAS MODALIDADES EN EL BARROCO MEXICANO}

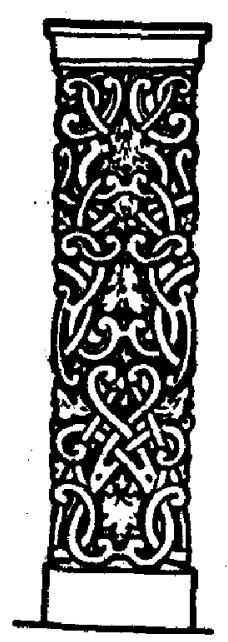

\section{BARROCO ESTUCADO (yeserías y argamasa)}

Es anástilo, marca la tendencia decorativa y no constructiva de la expresividad barroca. Respeta la estructura en que se aplica. Se sujeta a límites de composición. Es modelado y no labrado. Florece en la segunda mitad del siglo xvir, especialmente en Puebla y Oaxaca. 


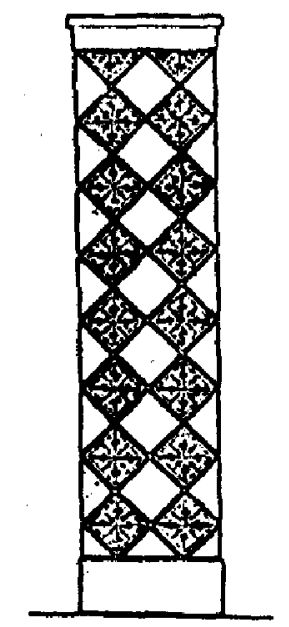

BARROCO TALAVERESCO

(barro vidriado y esmaltado)

Su caracteristica es el color al exterior. Modelado y poco constructivo, es un recubrimiento a manera de piel o traje que protege y complementa las formas arquitectónicas. Florece a mediados del siglo xviI, especialmente en Puebla y Tlaxcala.

\section{BARROCO PURISTA (apoyos clásicos)}

Usa el apoyo clásico en toda su pureza formal de composición y molduración, aunque no de proporción. Académico en columnas y pilastras, es libre en el resto de la composición y estructura. Sus mejores ejemplos son de mediados del siglo XVII, en el centro del pais.
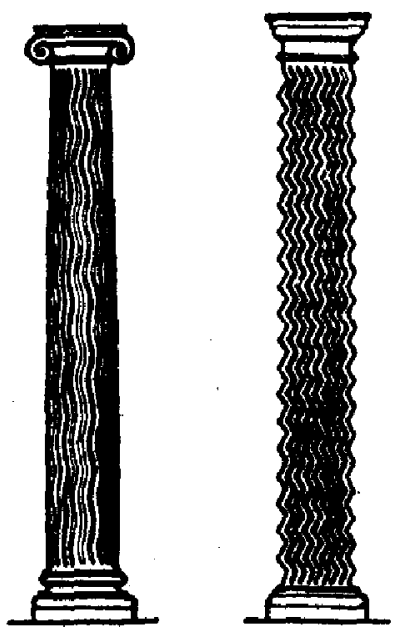

BARROCO DE ESTRIAS MÓVILES (ondulación y zigzag)

Primer paso importante en la transformación de los fustes. Modalidad caracterizada por el movimiento de las estrías ya sean ondulantes o zigzagueantes. Se hace más notable en las pilastras que, si ondulan, cobran aspecto de meandro $o$ al zigzaguear tienen perfil dentado o de acordeón. Las principales manifestaciones datan de principios del siglo xvin y se encuentran en el centro del país. 

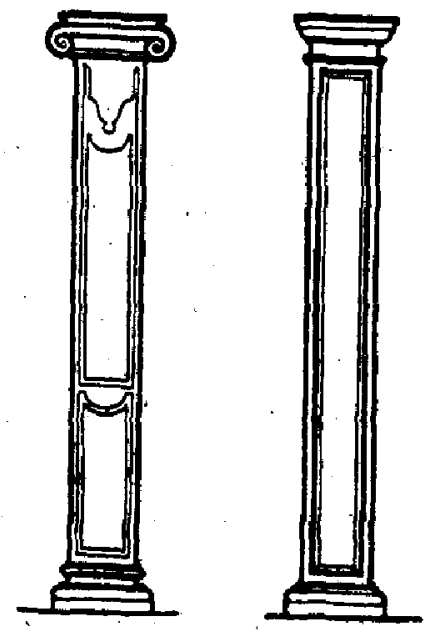

\section{BARROCO TABLERADO}

Fustes con aspecto de tableros de mueble. El Barroco muestra en esto su interés por transformar los fustes. Tiende a incorpo. rar de manera razonadamente geométrica una decoración suntuosa. Utiliza la guardamalleta y el trazo mixtilíneo. Empieza a negar la pesantez estructural, declara el sentido atectónico del estilo. Se manifiesta mayormente en la primera mitad del siglo xvili, en la zona centro y occidental del pais.

\section{BARROCO TRITOSTILO}

(de: tritos, tercio y stilos, columna)

Fustes de antecedentes clásicos, usados como esqueleto. Recuerda el renacimiento y plateresco, pero se reviste de vitalidad barroca escultórica. El fuste mueve sus volúmenes. El tercio marcado puede ser cualquiera o los tres a la vez. Se manifiesta en los limites de los siglos xviI y xvir, principalmente en Oaxaca.

\section{BARROCO SALOMÓNICO (helicoidal)}

El fuste se mueve en sí, no sólo por decoración o volúmenes añadidos. Es el mayor paso a la negación gravitacional de las estructuras, que asi sugieren ser imponderables. Se combina frecuentemente con el fuste tritóstilo. Se basa en antecedentes histórico-religiosos. Florece en los límites de los siglos XVII y xvIII, principalmente al centro y norte del pais. 


\section{BARROCO ESTIPITE (churrigueresco)}

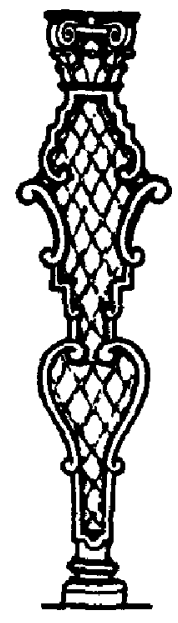

Cima de los hallazgos barrocos referidos al fuste arquitectónico. Permanece sujeto a cánones cons* tructivos, pero permite los mayores alardes y posibilidades plásticas, puesto que en sus pilastras los elementos son todos diferentes en diseño geométrico, lo que hace versátil el fuste. Su composición se relaciona con abstracciones del cuerpo humano. Sus mejores obras datan de mediados de la segunda mitad del siglo xvir, se extiende por todas las regiones del país creando escuelas locales.
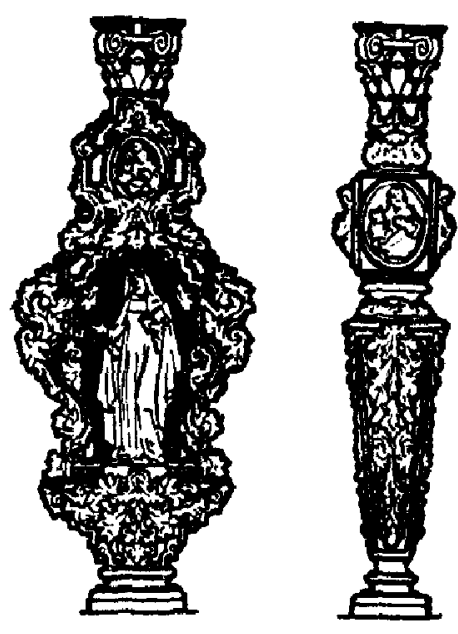

\section{ULTRABARROCO (pilastra-nicho)}

Es anástilo, cierra el ciclo decorativo del estilo. Se caracteriza por su arbitrariedad compositiva, producto de las libertades anteriores. No respeta, como el barroco estucado, las líneas directrices o compositivas de las estructuras que le rodean. Sus obras tienen carácter de mobiliario. Su esplendor imaginativo se agota en si mismo. Se produce a fines del siglo xvir. Deja sus mejores obras en el centro de lo que fuera Nueva España y desaparece con la presencia del neoclásico.

\section{NOTAS}

1 Francisco de la Maza, Mexican Colonial Relablos. Sobretiro de la Gazette des Beaux-arts, (sin datos bibliográficos), p. 183.

La palabra "andstilo" es usada por De la Maza para indicar la importancia del barroco mexicano, aun cuando se vea privado del apoyo arquitectónico en 
el concepto tradicional, asł dice que "antes de la definitiva desaparición del uso de los retablos, algunos muy interesantes se produjeron todavía caracterizados por la ausencia de columnas o pilastras, debido a lo cual yo los he llamado andstilos."

2 Constantino Reyes Valerio, Tepalcingo y Trilogia Barroca. Publicaciones 11 y 12 de la Dirección de Monumentos Coloniales I.N.A.H. México, 1960.

3 Manuel Romero de Terreros. Historia Sintética del Arle Colonial de México, México, 1922.

Al tratar de los caracteres de la arquitectura virreinal dice lo siguiente: "De la misma manera que Ponz llamó platerescos los edificios que por su profusa ornamentación recordaban las obras de los plateros, nosotros nos atrevemos a dar el dictado de talaverescos, a los edificios coloniales que están revestidos, en todo o en parte, con azulejos, por ser generalmente conocida esta cerámica con el nombre de "talavera de Puebla".

El arquitecto Federico Mariscal lo apellida "morisco mexicano".

4 Silvestre Baxter. La Arquitectura Hispano Colonial en México. Introducción y notas de Manuel Toussaint. México, 1934. p. 16, cap. v.

"Ladrillo Esmaltado (azulejos). En la Decoración Policroma de las Superficies. Otro rasgo arquitectónico general de México es el uso frecuente que se hace de los ladrillos esmaltados (azulejos) para decorar las superficies".

Baxter, al notar la importancia que en México tiene la aplicación del barro vidriado en la arquitectura, acertadamente le llama "ladrillo esmaltado", término que también, nos parece, sería correcto aplicar a la modalidad llamándola Barroco Esmaltado. Por otro lado; y dado el origen oriental del azulejo, hemos buscado la palabra árabe que lo identifica, la cual es ALKECHANL, sin embargo, el vocablo, pese a su interes, se presta poco en su extraña eufonia para denominar en alguna forma este tipo de barroco.

\section{Silvestre Baxter. Op. cit. p. 13.}

"La cúpula, una de las más nobles e impresionantes formas de la expresión monumental, es la caracterfstica arquitectónica predominante de este país. México es singularmente un pass de cúpulas. Fuera de Oriente probablemente ningún otro pueblo del mundo tiene tantas cúpulas, en el verdadero sentido de la palabra, es decir, sobre arcos de sólida mampostería. Casi todos los pueblos indios del México central tienen su iglesia cupulada. En pueblos insignificantes, que no están en el mapa general, se ven surgir racimos señoriales de cúpulas que serfan un acontecimiento en cualquiera de nuestras grandes ciu- 
dades. No hay exageración al decir que las cúpulas se encuentran en este país literalmente a millares".

6 Diego Angulo Iñiguez. Historia del Arte Hispanoamericano. Barcelona, España. Salvat Editores, S.A., 1956, tomo IIr.

En los capítulos IV a XII, escritos por Enrique Marco Dorta, y en los xIII a xvin por Mario J. Buschiazzo, al encontrarse con el tipo de pilastras que nosotros llamamos tableradas, ellos las denominan "cajeadas", por lo que coincidimos en considerarlas recipiente para otras ornamentaciones, o simplemente de formas planimétricas que con sus diferentes planos enriquecen el claroscuro.

7 De los ejemplos más antiguos de que se tiene noticia son los apoyos tritóstilos en el segundo cuerpo de la portada lateral de la catedral de San Luis Potosí (1680). Véase en el capitulo "Salvedades" la originalidad potosina al respecto.

8 Véase una aclaración más amplia en las "Salvedades" capitulo final de este trabajo.

9 Victor Manuel Villegas. El Gran Signo Formal del Barroco. Instituto de Investigaciones Estéticas. U.N.A.M., México, 1956.

Libro imprescindible para comprender la evolución del estípite desde Grecia hasta el barroco mexicano.

10 Dr. Atl. Iglesias de México. Publicaciones de la Secretarla de Hacienda, Méxíco, 1927. vol. vi, p. 144.

"No he dudado ni un momento, después de un largo estudio comparativo entre nuestros templos y los italianos, los españoles y los portugueses, de la necesidad de englobarlos dentro de una denominación que corresponda a su verdadero "ser", y he creado el vocablo ULTRA-BARROCO para indicar que vienen del Barroco y que van mds alld".

11. Diego Angulo Iñiguez. Op. cit. tomo If, cap. Xrv, p. 565.

Hablando del Sagrario Metropolitano de México dice que: "Lorenzo Rodríguez no se limita a emplear en la portada el estípite, sino que introduce en ella su hermano menor, el que podriamos llamar el INTERESTIPITE. Las estrechas calles laterales formadas por los estípites, en ese deseo del barroca de situarlo todo en el primer plano de nuestra atención, dejan de ser concebidas como un vano y se transforman en un nuevo soporte, que participa de las caracteristicas de los estipites que lo flanquean y del antiguo paramento inerte; de aquellos procede su perfil quebrado y de ésta la hornacina, qu suele decorar su parte central, es decir, el tema clásico del intercolumnio renacentista".

Más adelante, en el mismo tomo II, cap. xxIr, Angulo estudia con mayor detenimiento la evolución del interestipite en 12 rica gama variante de los re. 
tablos dieciochescos mexicanos, aunque sin mencionar lo que para nosotros es de gran interés; el avance hasta el primer plano, quizá por primera vez en la historia de la arquitectura, del intercolumnio, que siempre habia servido y permanecido en el fondo.

12 Joseph Baird. Eighteenth century retables of the Bajio, Mexico: The Queretaro Style. The Art Bulletin, vol. xv, 1. New York. Published by the College Art Association of America (Sept. 1953). The ornamental niche-pilaster in the Hispanic World. Journal of the Society of architectural Historians, vol. xv, 1. Urbana, Illinois. University of Illinois (March, 1956).

Baird sigue el rastro a la evolución de las hornacinas y observa que, desde fines del siglo xvir, existe "una tendencia a desarrollar nichos ornamentales quc eventualmente usurparían la articulación arquitectónica de columnas y pilas. tras". Ya en el siglo xvII, la iniciativa mexicana se muestra cada vez más atrevida e imaginativa y Baird considera que "la fachada de Tepotzotlán cs un ejemplo importante del triunfo gradual de la pilastra-nicho ornamental y to. davia es bellamente organizada". Para tener finalmente sus máximas manifestaciones en los retablos del Bajfo y en el "Queretaro Style", donde reina la pilastra-nicho, que nosotros consideramos representativa del ultrabarroco.

13 Justino Fernández. El Retablo de los Reyes, Estética del Arte de la Nueva España. México. Instituto de Investigaciones Estéticas. U.N.A.M., 1959.

Es necesario aclarar que el vocablo "ultrabarroco", acuñado por el Dr. Atl, ha hecho fortuna y es aceptado por la crítica en el sentido genérico que él le da para reconocer el sello personal del barroco mexicano en sus producciones de mediados a fines del siglo xvin.

La mayoría de los autores engloban en esta denominación, todos esos retablos y fachadas que exaltan la imaginación y que son un canto a la libertad creadora.

La personalidad, unida al efecto de estupefacción y riqueza que producen, hace que ultrabarrocas se denominen las más exaltadas creaciones del barroco estipite, así como los ricos estucados, como en Tonantzintla, o los retablos sobreabundantes queretanos; es decir, que el abigarramiento ornamental del siglo XvII, tan opuesto a las ponderaciones clasicistas, ha impreso en el barroco dos caras: una, la del siglo xvir, vuelta hacia la lejanía clásica, la otra, en el siglo Xvir, inconforme y revolucionaria. Esta última actitud que en México alcanza un clímax, es la que generalmente se califica de ultrabarroca.

En su libro sobre El Retablo de los Reyes, Justino Fernández muestra por primera vez, de manera sistemática, una visión panorámica de lo que la crítica, tanto nacional como extranjera, ha dicho respecto al arte de la Nueva España y reúne las opiniones más valiosas y certeras, que en su mayoría coinciden en aceptar, dentro del ultrabarroco, la gran producción del siglo xvirr mexicano. El mismo se declara, con razón, decidido partidario del calificativo genérico cuando dice, en las páginas 819 y 320 , que el churrigueresco es "modalidad 
importante del ultrabarroco, ya que en éste cabe el churrigueresco, el rococó y muchas otras formas, como las populares mexicanas... el retablo de los reyes es "churrigueresco", si se quiere, pero en plan más general es claramente: Ultrabarroco".

Con todo y lo discutible que ello pueda ser, nosotros conscientemente restringimos la denominación: "ultrabarroca", a solamente aquellas obras en que el barroco parece desprenderse de toda liga con su propio pasado y deja de tener normas arquitectónicas sistemáticas de composición, estructurándose, en cada caso, de manera particular y hasta peligrosa estéticamente.

Nuestro ultrabarroco muestra, asl, grandes coincidencias e influencias del rococó, aunque sin llegar a identificarse con él.

Por todas estas consideraciones, creemos que las últimas fases barrocas, las más significativas del estilo, son aún en mucho y seguirán siendo, materia de estudios que las diluciden. 